\title{
A VISÃO SINTÁTICA DE JÚLIO RIBEIRO
}

\author{
Ânderson Rodrigues Marins (UFF) \\ profandermarins@hotmail.com
}

\section{INTRODUÇÃO}

No cenário linguístico-historiográfico brasileiro, o período denominado gramática científica inicia com a publicação da Grammatica Portugueza, de Julio Ribeiro, em 1881. (CAVALIERE, 2000, p. 19). Nessa nova época, o método histórico-comparativo europeu passou a ser seguido nos estudos e obras acerca da língua portuguesa. Assim, nossa historiografia começava a dar seus passos iniciais no século XIX, surgindo eminentemente marcada pela influência de autores de origem inglesa e alemã. A história da língua nacional passou a ser escrita com um maior senso de objetividade graças à contribuição do espírito germânico. Esse espírito se expressa na maior preocupação com os dados objetivos, na leitura atenta das fontes documentais (objetividade dos documentos) e através da isenção de preconceitos e orientações tendenciosas.

Julio Ribeiro inaugurou o modo de encarar os fatos gramaticais como método de investigação científica, modernizando os estudos dessa área, partindo do exame objetivo e imparcial da realidade idiomática, afastando as orientações do ensino de nossa língua materna da gramática filosófica. Para isso buscou os novos procedimentos adotados pelos estudiosos alemães, ingleses e franceses, tendo deveras, como autor de uma gramática, um lugar de responsabilidade como intelectual e uma posição de autoridade em relação à singularidade da língua portuguesa no Brasil.

Alguns princípios historiográficos, como o caso da influência (KOERNER, 1995, p. 19), orientam quanto à natureza e o objetivo da obra de J. Ribeiro, porquanto o filólogo brasileiro não oculta sua busca às bases teóricas europeias para compor seu trabalho. Como Cavaliere assevera: "De Bain absorve o minucioso modelo de apresentação da teoria gramatical, mediante divisão binária em lexeologia e sintaxe" (CAVALIERE, 2000, p. 53). Ante os conceitos das dicotomias continuidade (= permanência) x descontinuidade (= ruptura) (KOERNER, 1995, p. 15), a Grammatica de Julio Ribeiro re- 
presenta uma ruptura com as ordens teóricas metafísicas então vigentes no tradicionalismo gramatical do século XIX no Brasil.

Enquanto objeto histórico de que se pode dispor para a sociedade brasileira, a gramática constitui lugar de construção e representação de unidade e de identidade. Ao trazerem para si o ato da autoria, os primeiros gramáticos brasileiros como Julio Ribeiro, João Ribeiro, Maximino Maciel, Lameira de Andrade e Pacheco Silva, e outros, participaram da construção do Estado brasileiro. A partir da segunda metade do século XIX, os estudos da língua portuguesa no Brasil começaram a ganhar um caráter destacado e específico dentro do ambiente intelectual da época. Desde então, por um lado, muitos pensadores se dedicaram a demonstrar que o português falado no Brasil era diferente do português falado em Portugal e, por outro, desenvolveu-se um movimento de gramatização brasileira do português que produziu tecnologias e instrumentos linguísticos tais como dicionários e gramáticas (GUIMARÃES; ORLANDI, 1996, p. 127). E dentro deste processo de gramatização, a filologia desempenhou um papel importante, servindo de base teórica e científica para a preparação dos instrumentos linguísticos que foram produzidos no final do século XIX e ao longo do século XX.

O contexto sociocultural do pensamento positivista também influenciou na análise dos fatos gramaticais, ao contribuir para que se tivesse como paradigma a ordem e a pesquisa empírica, e que a veracidade dos fatos fosse comprovada cientificamente. Consoante Sevcenko (2003):

As décadas situadas em torno da transição dos séculos XIX e XX assinalaram mudanças drásticas em todos os setores da vida brasileira. (...) Os fenômenos históricos se reproduziram no campo das letras, insinuando modos originais de observar, sentir, compreender, nomear e exprimir. (SEVCENKO, 2003, p. 286)

Logo, nos anos entre 1880 e 1930, sobressaiu uma tendência gramatical de clara inspiração positivista, assinalando uma legítima inflexão na escrita gramatical que vinha se estendendo ao longo de todo o século XIX, cuja referência era, certamente, a Grammaire Génerale et Raisonnée de Port-Royal (1660).

É assim que a publicação da Grammatica Portugueza (1881), de Julio Ribeiro, que por ser de extração positivista, inaugurou no 
Brasil uma visão da linguagem como um conjunto de preceitos científicos positivos, que devem ser seguidos como normas prescritivas invariáveis.

Dos diversos nomes que compõem a tradição gramatical brasileira, aqueles que se incorporam nos limites dos cinquenta anos aqui determinados formam um grupo distinto. Isso se deve não apenas por se situarem nesse período nomes que serviriam de modelo teórico para todos os estudos gramaticais brasileiros posteriores, mas especialmente por se tratar de uma época mediadora entre um modelo gramatical firmado numa tradição clássica de natureza filosófica - da qual a Grammatica Philosophica da Lingua Portugueza (1822), de Jerônimo Soares Barbosa, viria a ser uma das mais expressivas representantes - e uma nova perspectiva linguística, vigente durante quase todo o século XX, de natureza científica.

Esse período da historiografia gramatical agrupa, portanto, figuras exponenciais de magnífica distinção no conjunto de autores de gramáticas produzidas no Brasil, a principiar por Julio Ribeiro, que de fato inaugurou no âmbito da construção gramatical, o método histórico-comparativo. Vindo após ele, gramáticos como João Ribeiro, Maximino Maciel, Manuel Pacheco da Silva Júnior, Lameira de Andrade, Eduardo Carlos Pereira, entre outros. Se do ponto de vista teórico se inspiraram nos pressupostos teóricos positivistas que avançaram século $\mathrm{XX}$ adentro, do ponto de vista prático, apoiaram-se nas modificações promovidas no ensino brasileiro, a partir de 1870, sobretudo com o desempenho de Fausto Barreto na direção do Colégio D. Pedro II.

Assim sendo, do conjunto das contribuições trazidas por Júlio Ribeiro aos nossos estudos gramaticais, o objetivo deste artigo consiste em analisar a visão sintática do filólogo na Grammatica Portugueza (1911). Fica, no entanto, certo, que à natureza deste trabalho impõe-se uma apreciação concisa de fatos que requerem maior atenção em local e momento oportunos.

\section{A SINTAXE NA GRAMMATICA PORTUGUEZA}

Pour les langues, la méthode essentielle est dans la comparaison et la filiation. - Rien n'est explicable 


\section{DEPARTAMENTO DE LETRAS}

dans notre grammaire moderne, si nous ne connaissons notre grammaire ancienne (LITTRÉ, $a$ pud RIBEIRO, 1911, folha de rosto).

Pelo princípio da contextualização (KOERNER, 1995, p. 17), a epígrafe utilizada como amparo doutrinário por Julio Ribeiro em sua Grammatica Portugueza (1911) ratifica que a obra é de caráter histórico-comparativo.

O filólogo não oculta sua consideração às teorias linguísticas de Willian Dwight Whitney: "Abandonei por abstractas e vagas as definições que eu tomára de Burgraff: preferi amoldar-me ás de Whitney, mais concretas e mais claras" (RIBEIRO, 1911, p. 1). É de Whitney em Essentials of English Grammar (LONDON, 1887), inclusive, a concepção de gramática assumida por Ribeiro: "Grammatica é a exposição methodica dos factos da linguagem" (RIBEIRO, 1911, p. 7).

Do uso dos termos exposição e factos, podemos depreender que a postura adotada não é normativa, porém descritiva. $\mathrm{O}$ próprio Ribeiro elucida melhor o assunto:

A grammatica não faz leis e regras para a linguagem; expõe os factos della, ordenados de modo que possam ser aprendidos com facilidade. $\mathrm{O}$ estudo da grammatica não tem por principal objecto a correcção da linguagem. Ouvindo bons oradores, conversando com pessôas instruidas, lendo artigos e livros bem escriptos, muita gente consegue fallar e escrever correctamente, sem ter feito estudo especial de um curso de grammatica (RIBEIRO, 1911, p. 7).

Cabia ao gramático descrever o que se entendia como norma culta escrita, ao discriminar como impróprios para a descrição proposta os fatos não descritos, trazia consigo uma normatização tácita (CAVALIERE, 2000, p. 47).

Nas palavras de Margarida Petter (2004):

A tarefa do gramático se desdobra em dizer o que é a língua, descrevê-la e, ao privilegiar alguns usos, dizer como deve ser a língua. $\mathrm{Na}$ verdade, a conjunção do descritivo e do normativo efetuada pela gramática tradicional opera uma redução do objeto de análise que, de intrinsecamente heterogêneo, assume uma só forma: a do uso considerado correto da língua. (PETTER, 2004, p. 19)

O projeto de fazer da gramática um registro do estado do português escrito e falado pelas pessoas cultas da época, levou Julio Ri- 
beiro a registrar numerosas observações, além de oferecer seu próprio testemunho como exemplo dos fatos linguísticos. Em face dessa atitude, de extensa aplicação na linguística descritiva, obteve injusta crítica de alguns que a ele se opunham, como Maximino Maciel: “... $\mathrm{E}$, quanto à sintaxe, ao invés de exemplos hauridos aos monumentos literários, dava-lhos ele próprio, quase sempre" (MACIEL, apud BECHARA, 2006, p. 15).

Maciel na sua Grammatica Descriptiva (1914), "baseada nas doutrinas modernas", forneceu-nos seguro painel das influências estrangeiras na gramática brasileira, encontradas no rodapé de cada página, onde faz referência às fontes que consultou. Assegura que "assim procedemos, porque a probidade scientifica aconselha citar-se um autor, desde que lhe estejamos de accordo com as opiniões attinentes a um ponto, para mostrarmos as fontes a que recorremos". E quanto à sintaxe sanciona:

Ainda nos esforçamos por estudar a lingua nos seus monumentos literarios, consolidando-lhe por isso os factos e a doutrina com exemplos selectos, hauridos aos principaes escriptores que se nos afigurou poderem servir de normas á syntaxe da lingua. (MACIEL, 1914, prólogo)

A descrição gramatical em Ribeiro constitui-se da bipartição lexeologia e syntaxe, aquela "considera as palavras isoladas, já em seus elementos materiaes ou sons, já em seus elementos morphicos ou fórmas", esta "considera as palavras como relacionadas umas com as outras na construcção de sentenças, e considera as sentenças no que diz respeito á sua estructura, quer sejam simples, quer se componham de membros ou de clausulas" (RIBEIRO, 1911, 3, p. 221). Assim, apreendemos que a palavra ocupa o núcleo das atenções, na lexeologia e na sintaxe. Não obstante esta última constitua a segunda parte do raciocínio gramatical, na prática não vai além de uma dilatação da primeira.

Da gramática inglesa Ribeiro importou a concepção de clausulas e elucida: "Chamam-se clausulas os membros da sentença, quando são tão connexos entre si que um depende do outro e até o modifica" (RIBEIRO, 1911, p. 223). Maximino Maciel na Grammatica Descriptiva (1914, p. 326-7) adotaria, em detrimento de clausulas, phrases, setenças ou orações o termo proposições, "por ser este mais geral e estar mais de accordo com as theorizações da logica e simplificar mais a aprendizagem", às quais se relacionavam três ou- 
tros conceitos: coordenação, quando independentes entre si, subordinação, quando dependentes entre si e coordenação e subordinação, quando duas ou mais proposições, além de independentes ou coordenadas entre si se acham cada uma delas desenvolvidas por proposições subordinadas.

Outra questão notável que cumpre destacar reside nos casos abaixo analisados por Julio Ribeiro:

a) A idéia que se liga ao sujeito: chama-se predicado propriamente dito.

b) O laço que prende o predicado propriamente dito ao sujeito: chama-se copula.

Pedro ama, - ama decompõe-se em am thema, e $a$ terminação: o thema am fica tido como predicado propriamente dito, e a terminação $a$, como copula. (RIBEIRO, 1911, p. 222-3)

A morfossintaxe, consolidada a partir da segunda metade do século XX, bem antes, porém, já se podia depreender na análise supracitada de Julio Ribeiro como conexão das categorias gramaticais às funções sintáticas na sentença. Fê-lo realizando um dos primeiros casos de análise morfossintática. Assim, Ribeiro considera um ponto de atrelagem entre a morfologia e a sintaxe: "a copula grammatical de todas as sentenças consiste na flexão do verbo" (RIBEIRO, 1911, p. 223).

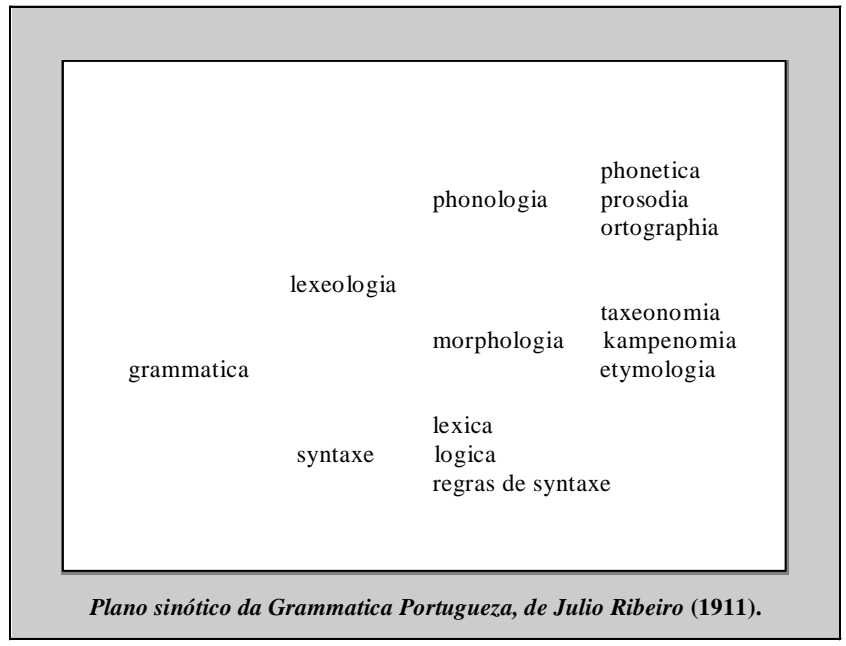


Em sua proposta descritiva Ribeiro (1911, p. 223) subdivide a sintaxe em léxica e lógica, aquela referente ao estudo das "palavras como relacionadas umas com as outras na construcção de sentenças", esta ocupada do estudo das "sentenças no que diz respeito á sua estructura, quer sejam ellas simples quer sejam ellas compostas", isto é, a primeira ocupa-se das palavras inter-relacionadas na oração, a segunda da estrutura das orações. Cumpre ressaltar que na proposta descritiva da sintaxe Ribeiro analisa a relação e não a função sintática. Na estrutura de Ribeiro interatuam vocábulos, não sintagmas. O que se apresenta é uma relação direta, termo a termo, em forma de:

1) Relação subjetiva: A do sujeito para com seu predicado.

2) Relação predicativa: Em que o predicado de uma sentença está para com seu sujeito.

3) Relação atributiva: A da palavra que representa alguma qualidade com a que representa a coisa.

4) Relação objetiva: Em que está para com um verbo de ação transitiva o objeto a que se dirige, ou sobre que exerce essa ação.

5) Relação adverbial: A que vincula uma dada palavra a um adjetivo, verbo ou a um advérbio.

Para Ribeiro nas sentenças: Pedro é rico (p. 224), está em relação subjetiva; $O$ menino corre (p. 225), o verbo corre está em relação predicativa com o sujeito menino; A casa de Pedro (p. 225), o substantivo precedido da preposição de está em relação atributiva com casa; em O cão levantou a cabeça (p. 226), o substantivo cabeça está em relação objetiva para com o verbo levantou; na sentença Paulo deu-me um livro (p. 226), o pronome pessoal incluído como complemento verbal está em relação objetiva - adverbial.

Ademais, Julio Ribeiro (1911, p. 257-8) delineia concisa anotação sobre a presença do emprego pleonástico dos pronomes substantivos em relação subjetiva, objetiva, adverbial e objetiva adverbi$a l$ em várias línguas românicas, como se observa a seguir:

Estes processos pleonasticos, que contribuem muito para a clareza e elegancia da expressão, encontram-se em varias linguas romanicas, em Latim barbaro, em Latim classico, em Grego moderno, em velho Alto Allemão, em Inglez, em Dinamarquez, em Sueco. (RIBEIRO, 1911, p. 259) 
E ainda sobre a questão do pronome substantivo sujeito de um verbo no infinito, dependente de um verbo no finito, posto em relação objectiva:

Esta syntaxe, commum a varias linguas romanicas, é tomada directamente do Latim, em o qual o sujeito do verbo no infinito vai para o accusativo. E' erro vulgar no Brazil usar-se em casos taes da relação subjectiva: diz-se, por exemplo: Vi ELLE caminhar ás pressas. - Deixa ELLE ir. (1911, p. 262)

Estes fragmentos constituem exemplos significativos do bom agasalho que se deu ao método histórico-comparativo no Brasil. Produtivo não somente em trabalhos de pesquisa, mas ainda em compêndios gramaticais, o referido método favoreceu o critério de preocupação com a evolução da língua, fato que se pode corroborar nas palavras do próprio Julio Ribeiro: "Nós temos mais de estudar as fórmas varias porque passou a nossa lingua, temos de comparar essas fórmas com a fórma actual, para que melhor entendamos o que esta é e como veiu a ser o que é” (RIBEIRO, 1911, p. 1,2).

Por fim, cabe-nos ainda observar que a produção gramatical brasileira a partir de Julio Ribeiro, em meio às alterações de observação e reflexão sobre o estudo do vernáculo, reflete um diálogo tanto com a tradição greco-latina quanto com a corrente científica. Assim, vivia-se um momento de transição e mudanças, não só de âmbito intelectual, mas ainda político e social, que de certa maneira, a língua não poderia deixar de registrar. Consideremos o valor que se deve dar à gramática científica no cenário linguístico-historiográ-fico brasileiro, pois:

O que se percebe de notável, (...) é que o elenco de obras filológicas produzidas a partir do trabalho inaugural de Julio Ribeiro cria os fundamentos da moderna gramática brasileira, nos moldes em que, mutatis mutandis, até hoje se organizam. (CAVALIERE, 2000, p. 55)

\section{REFERÊNCIAS BIBLIOGRÁFICAS}

BECHARA, Evanildo Cavalcante. A contribuição de M. Said Ali à lingüística portuguesa. In: ALI, M. Said. Investigações filológicas. 3. ed. rev. e ampl. Rio de Janeiro: Lucerna, 2006.

CAVALIERE, Ricardo Stavola. Fonologia e morfologia na gramática científica brasileira. Niterói: EdUFF, 2000. 
. Uma proposta de periodização dos estudos linguísticos no Brasil. Confluência: Revista do Instituto de Língua Portuguesa. Rio de Janeiro: Liceu Literário Português, no 23, 2002.

GUIMARÃES, Eduardo; ORLANDI, Eni P. (Orgs.). Língua e cidadania. Campinas: Pontes, 1996.

KOERNER, Konrad. Persistent issues in linguist historiography. In: . (ed). Professing linguistic historiography. Philadelphia: John Benjamins Publishing Company, 1995.

MACIEL, Maximino de Araujo. Grammatica descriptiva. 5. ed. Rio de Janeiro: F. Alves, 1914.

PETTER, Margarida. Linguagem, língua, lingüística. In: FIORIN, J. Luiz. (Org.). Introdução à lingüística. São Paulo: Contexto, 2002.

RIBEIRO, Julio. Grammatica portugueza. 10. ed. Rio de Janeiro: F. Alves, 1911.

SEVCENKO, Nicolau. Literatura como missão: tensões sociais e criação cultural na Primeira República. 2. ed. São Paulo: Cia. das Letras, 2003. 